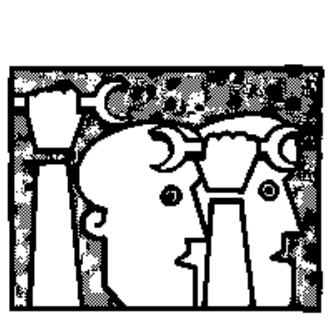

\title{
Saúde mental e trabalho: uma urgência prática.
}

\section{WANDERLEY CODO USP-R.PRETO}

Embora alguns pesquisadores gostem de considerar as pesquisas sobre Saúde Mental e Trabalho como uma "área nova", já em 1917, quando o Dr. Freud publicava suas "Noções introdutórias sobre Psicanálise", o primeiro número do jornal "Mental hygiene" trazia um artigo alertando para o fato de que "pacientes desempregados apresentam sérios problemas, agrupados em três classificaçöes: personalidades paranóides, personalidades inadequadas $e$ instabilidade emocional', dois anos depois Southard foi solicitado pela "Engineering Foundation of New York" a investigar "problemas emocionais entre os trabalhadores". Em 1933 foi aprovada a jornada de 6 horas para os bancários, argumentando-se com bases na "psiconeurose bancária".

Não poderia ser de outra forma: qualquer estudioso sabe que tem obrigaçāo de partir de alguns pressupostos sem o qual o seu trabalho se torna impossivel, assim um biólogo que queira estudar uma espécie, um tamanduá, por exemplo, deve partir do que a espécje é, ou seja, do que o diferencia do não-tamanduá. Caso esta resposta, a priori, nảo seja possível há que partir do que o animal faz, como sobrevive. Mais do que isto, os biólogos sabem que uma resposta leva a outra.

Destes parâmetros, a Psicologia (também) não escapa. $O$ que diferencia os Homens dos outros animais?: Seu Trabalho. Como Sobrevivemos? Pelo nosso trabalho. Se quisermos ser mais pretensiosos, o que ESTE Homem é? Qualquer que seja a resposta a estas questões, impossível se afastar das condições concretas em que ESTE Homem vive.

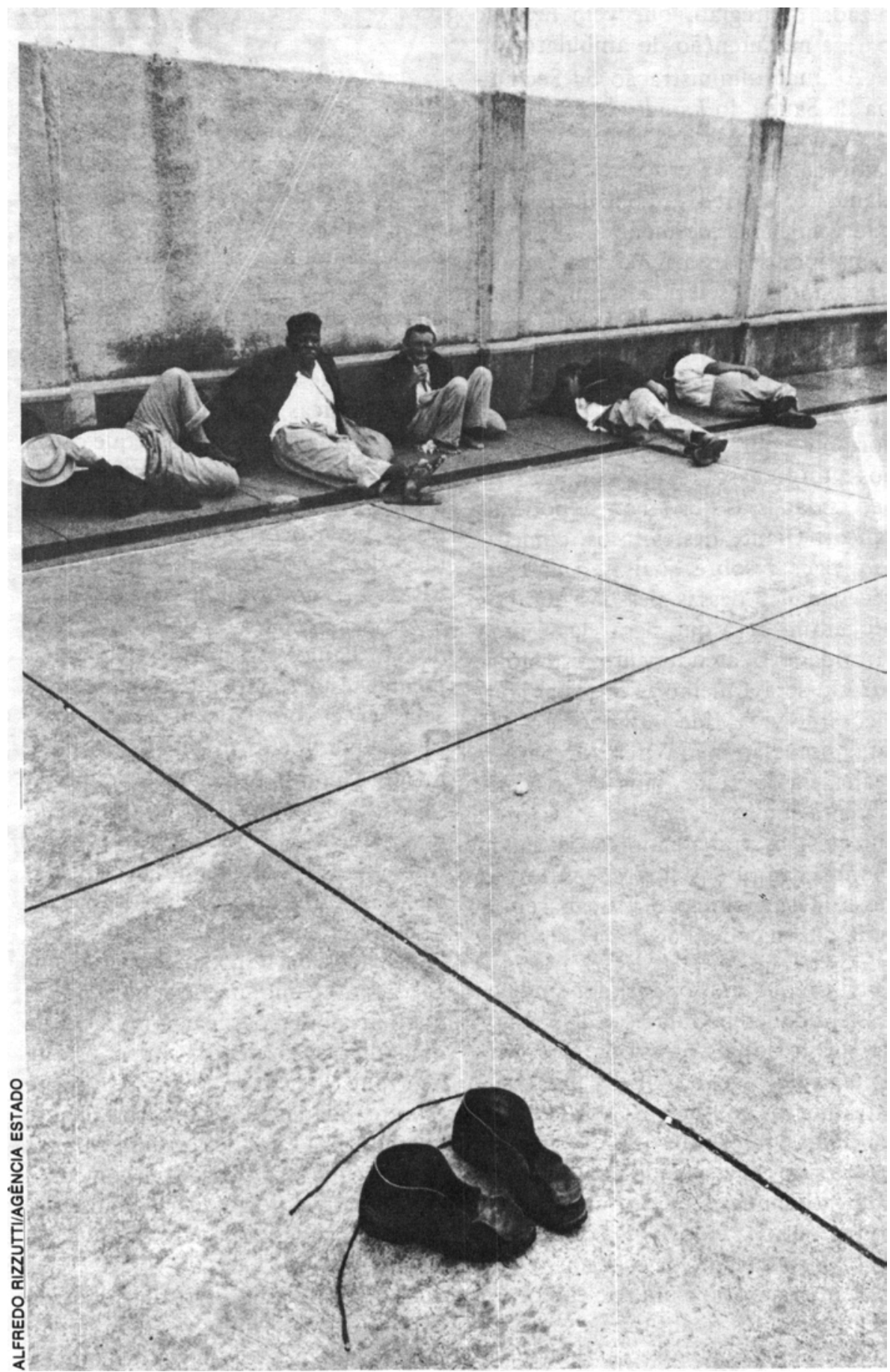


Se antiga e óbvia é a constatação de que a vida dos homens explica a vida dos homens, infelizmente isto não significou grandes avanços do ponto de vista técnico-teórico. Por razōes que discutimos em um outro artigo, ainda hoje encontramos autores como Alan Mc. Lean, considerando, de um lado, que "as relações entre a satisfação e o trabalho têm sido largamente sugeridas, por vezes assumida, mas permanece sem provas"... $\mathrm{Na}$ outra ponta autores como o clássico de Le Guillant, reportando "A neurose das telefonistas", ou Wisner, apontando para o trabalho como capaz de "fazer surgir manifestações que configurariam esta síndrome"... ou ainda Bugard e Crocq que consideram o trabalho apenas como desencadeante de sintomas em pessoas já portadoras de "neurose latente". Em nossas pesquisas, temos procurado desenvolver a hipótese de que o trabatho teria função determinante, embora não exclusiva nos distúrbios mentais.

Tal miríade de interpretações tem sido apontada como uma das causas para que as descobertas neste território não desdobrem em providências práticas visando proteger a saúde mental do trabalhador. Veremos adiante se esta assertiva se justifica.

As pesquisas e publicações denunciando o comprometimento da Saúde Mental e Trabalho proliferam, a consciência dos trabalhadores mais atingidos (como os bancários) admite sem surpresas o risco da "loucura" $e$, no entanto, nenhuma providência concreta a nível preventivo ou remediativo é tomada. Sobre a "doença mental" paira uma espécie de conluio do silêncio, a sociedade se cala, restringe a atuação aos consultórios e hospitais especializados, como a lepra há alguns anos, tudo se passa como se estivéssemos diante de uma realidade que envergonha a sociedade ou a família, a ser confinada, não apenas longe de nossos olhos, mas principalmente de nossas consciências.

No entanto, segundo as precárias estatísticas oficiais, os transtornos neuróticos são os responsáveis pela segunda causa em magnitude na "incapacidiade temporária" ao trabalho. $O$ alto ritmo de informatização desloca do braço para o cérebro o principal desgaste do trabalhador. $O$ capitalismo cada vez mais monopolizado e financeiro empurra uma massa de trabalhadores para ofícios onde a questão não é mais a da "desvinculação entre o produto e o produtor" mas a inexistência mesma do produto, trabalho "vazio", carente de valor de uso, trabalho que impede a conformação da identidade de quem o realiza. A recessão carrega o aumento brutal do desemprego e com ele o desamparo. Enfim, cada vez mais se torna urgente uma ação concreta buscando prevenir/remediar/conhecer os efeitos desta nossa velha crise sobre a Saúde Mental dos nossos trabalhadores, cada vez mais se torna incômoda a sensação doce de "pasmo" erudito que nós, Psicólogos e Psiquiatras, elegemos como nossa profissão.

\section{O que? E como tazer?}

Impossivel discordar com o documento distribuido neste encontro quando se propōe a uma "delimitação do campo de ação em saúde mental": " $\hat{A}$ totalidade da população compete-nos a comunicação de conhecimento sobre quais e como os fatores ambientais, sociais, familiares, individuais e genéticos podem atuar no sentido de favorecimento à saúde mental, ou inversamente, ao adoecimento mental... Há sem dúvida conhecimentos a serem debatidos com a população, como por exemplo, os efeitos psíquicos das intoxicaçōes pela poluição industrial ou pela agroindústria... pelo "stress" crônico do trabalho penoso e alienante..."

Embora todos nós reconheçamos a importância dos "movimentos de conscientizaçāo", somos também todos nós forçados a reconhecer que são insuficientes quando se trata de combater condiçōes objetivas. $O$ mascaramento da doença mental atende a forças econômicas e políticas eviden. tes, desnecessário inumerá-las aqui, por elas a doença mental se vê alijada aos porōes da sociedade, produto indesejável, vergonhoso dela mesma que sempre foi.

Trago a debate, neste fórum nacional, a proposta de que as Doenças Mentais sejam consideradas, para efeitos legais como Doença Profissional, enquadrando-a na lei n. 6.367 , de
1976, ou seu equivalente a ser elaborada pela Constituinte, equiparandoa, portanto, como qualquer outra doença profissional ou do trabalho, a um acidente de Trabalbo, pois atualmente as doenças "psíquicas" nāo são atingidas por aquela legislação.

A razão maior da existência desta mesa-redonda é a proximidade da Constituinte; nos interessa passar cm revista a legislação sobre saúde/doença mental e contribuir ao debate. No entanto, no que tange à minha contribuição, creio que o seu locus mais apropriado seja o que os juristas chamam de legislação ordinária, o que nos permite mais tempo para debate da proposta que apresento aqui.

Antes de discutir a lei e as possibilidades de enquadramento, alinharemos as razöes que embasam nossa proposta.

Existe uma vantagem econômica (aliás, irrisória) para o trabalhador quando acidentado, se conclui tratarse de um acidente de trabalho, por exemplo o período de inatividade provocado por causas outras é "remunerado" a cerca de $70 \%$ do seu pagamento atual, nos casos de doenças profissionais chega-se a algo em torno de $90 \%$ do salário percebido, além disso podem ocorrer indenizaçöes, pecúlios e outros itens. No entanto, não nos parecem ser estas as razões para a inclusão da doença mental, mesmo porque, ao corpo e/ou espírito mutilado, incapaz para - trabalho, qualquer remuneraçāo é pouca e a definida atualmente, irrisória. Nossa defesa vai em outra direção:

O possível enquadramento das doenças mentais como "doença profissional" arranca a discussão e o diagnóstico do foro privado e o remete a uma instância pública, necessariamente política.

1. Do ponto de vista do Trabalhador, deve fazer bem o reconhecimento de que sua loucura não é tão sua como parecia, é produto das suas condições objetivas de vida, ameaça de sua classe, portanto, pelo menos não haveria mais razões para escondê-la do mundo. Abre-se a possibilidade de reivindicações por um ambiente de trabalho psicologicamente sadio, arquitetam-se modos de aferição dos mesmos, enfim reduz-se a impotência pe- 
rante o "stress" e a tensão no trabalho. Um processo onde bancários reivindicassem mudanças na estrutura de trabalho, reduzindo a probabilidade do que Dejour chamou de "sindrome subjetiva pós-traumática", por exemplo, promoveria "a socialização dos conhecimentos", até agora de posse dos profissionais especializados, "de forma democrática, participativa e dialética".

2. Do ponto de vista da empresa, haveria razōes objetivas para uma maior preocupação com investimentos em mudanças na estrutura organizacional de trabalho, visando eliminar ou diminuir fatores de risco a saúde mental.

3. Do ponto de vista do Estado, mobilizar-se-ia, sob riscos de arcar com os prejuizos, para uma fiscalizaçāo dos ambientes de trabalho no que tange ao bem-estar psíquico, assim como investiria em pesquisas visando à detecção em caráter preventivo dos fatores de risco ou em modos alternativos de organização do trabalho nos casos em que o comprometimento mental já está detectado, como na informática, por exemplo.

4. Do ponto de vista dos profissionais que fizeram da lide com a saúde mental sua profissão, seríamos convocados a emitir laudos, ou pelos tribunais, ou por representantes de trabalhadores, ou patronais. Com isso, substituímos o soliloquio das "linhas e áreas" imiscíveis cm que nos aprisionamos, por um acirrado debate público, onde a competência tomaria - lugar da mera sedução. Veríamos necessariamente crescer as contribuiçōes cientificas que abordassem a loucura a partir das condições sociais concretas, nossas formulaçōes se tornariam obrigatoriamente menos exotéricas. Não é do confronto com a vida que a ciência se nutre? Não é o rigor objetivo que differencia a ciência do ocultismo?

Acidentes de Trabalho, acidentes profissionais, doenças profissionais, a Lei $6.367,1976$ e toda a legislação que "protege o trabalhador" das mazelas do trabalho são a revelação mais eloquiente, e por isso mais cruel, do caráter das relaçōes trabalho-capital, porque são a manifestação pública de uma contradição com vocação subterrânea. Em seu modo corrente, o estabelecimento do contrato de traba22 PSICOLOGIA, CIÉNCIA E PROFISSÃo tho assume a configuraçāo entre um 'livre' vendedor e 'livre' comprador de força de trabalho, mascarando por isso a outra face do trabalho, sua transformação em mercadoria como outra qualquer. Fundamentalmente 0 dinheiro permite e concretiza este duplo caráter: De um lado a presença de um trabalhador, indivíduo em sua legítima expressão, cidadão cm exercício da soberania tal como se apresenta no consumo. Do outro et pour cause, mero instrumento de produção de valor genérico, artífice da expropriação de si mesmo. Perante um acidente de trabalho a dupla representação se esvai, a venda do corpo a preços de mercado aparece exatamenté como a venda do corpo a preços de mercado, e o marceneiro que perdeu o dedo recebe em troca uma indenização, maior quanto mais prejudicado estiver a força de trabalho a ser vendida amanhã, medida com requintes anatômicos (a falange dos destros vale uma indenização maior do que o equivalente da mão esquerda). Agora o trabalho assumiu uma representação unívoca; mercadoria como outra qualquer, comprada a preço de sua reprodução, indenizada na medida da sua venda futura. $O$ outro braço, livre, artifice da subjetividade humana, desapareceu durante o processo que corre entre o INAMPS ou nas malhas da justiça do trabalho, e só foi possível ignorá-lo porque ele já não estava na fábrica.

Por ser sintético, $o$ acidente de trabalho e a legislação trabalhista permitem a recorrência, a revelação do duplo caráter da mercadoria (seu valor de uso e de troca) e da força de trabatho enquanto mercadoria, promotora da identidade e usurpadora do sujeito. Entre o trabalho e a força de trabalho as discussōes sobre segurança $e$ suas legislaçōes se concretizam, para em seguida eliminar o trabalhador. Se é mister reconhecer a crueldade importa também reconhecer que a legislação trabalhista não é o demiurgo da alienação do trabalhador de seu próprio corpo, mas sim apenas a manifestação sincrética e pública daquela conformação que o trabalho já assumira, e aqui residem as suas contradições.

De um ponto de vista concreto (con-crescere) a luta dos trab: lhadores passa necessariamente por impu- tar à fábrica (por exemplo) a responsabilidade por sua saúde ou doença, exigir dela os ressarcimentos sobre a força de trabalho danificada. Aos donos dos meios de produçāo compete a tarefa avessa, o que implica uma atribuição pelo acidente à própria vítima, em última instância recortando no trabalhador a figura de um sujeito "responsável por seus atos"; um indivíduo livre. No jargāo jurídico a disputa assume a forma de comprovação sobre o nexo causal, a quem pode ser atribuido o acidente. Nesta farsa cada qual transveste pelo avesso os seus próprios desígnios. Para o trabalhador que pode responsabilizar a fábrica pelo seu corpo resta a ratificação jurídica de sua impotência, ganhar a luta jurídica significa o reconhecimento da transformação do seu corpo em mera força de trabalho, amputar do braço sua dimensão humana, subjetiva, a vitória implica destruição da capaçidade de autodeterminação. $\mathrm{Pa}$ ra a fábrica a absolvição se identifica à livre determinação do indivíduo, em última instância, a ruptura com a sua própria essência, compradora da força de trabalho.

$\mathrm{Na}$ outra face do infortúnio está o reconhecimento jurídico, portanto público, do caráter predatório do trabalho nestas relações de produção, e pelo avesso um instrumento importante de "conscientização" do trabalhador, no sentido de reapropriação do seu próprio corpo. Na medida em que expulsa da tragédia a ideologia da culpa individual, da incompetência. Quando a legislação de acidentes de trabalho consagra a responsabilidade do empregador, pode realizar o trânsito entre as representações individualistas e o caráter coletivo do trabalho, por isso da segurança no trabalho; uma visão coletiva da relação saúde-doença. Até agora a pendenga jurídico-técnica que percorre os acidentes de trabalho diluiu-se em seu verdadeiro locus: nem mais nem menos do que aguerrida luta de classes, porque reveladora do duplo caráter do trabalho em nossa sociedade, porque confronta o trabalho/trabalho e o trabalho/mercadoria - o indivíduo, o sujeito, o cidadão contra o capital, a mercadoria, a força de trabalho. Porque tal disputa assume o caráter público, político. No seio desta guerra 


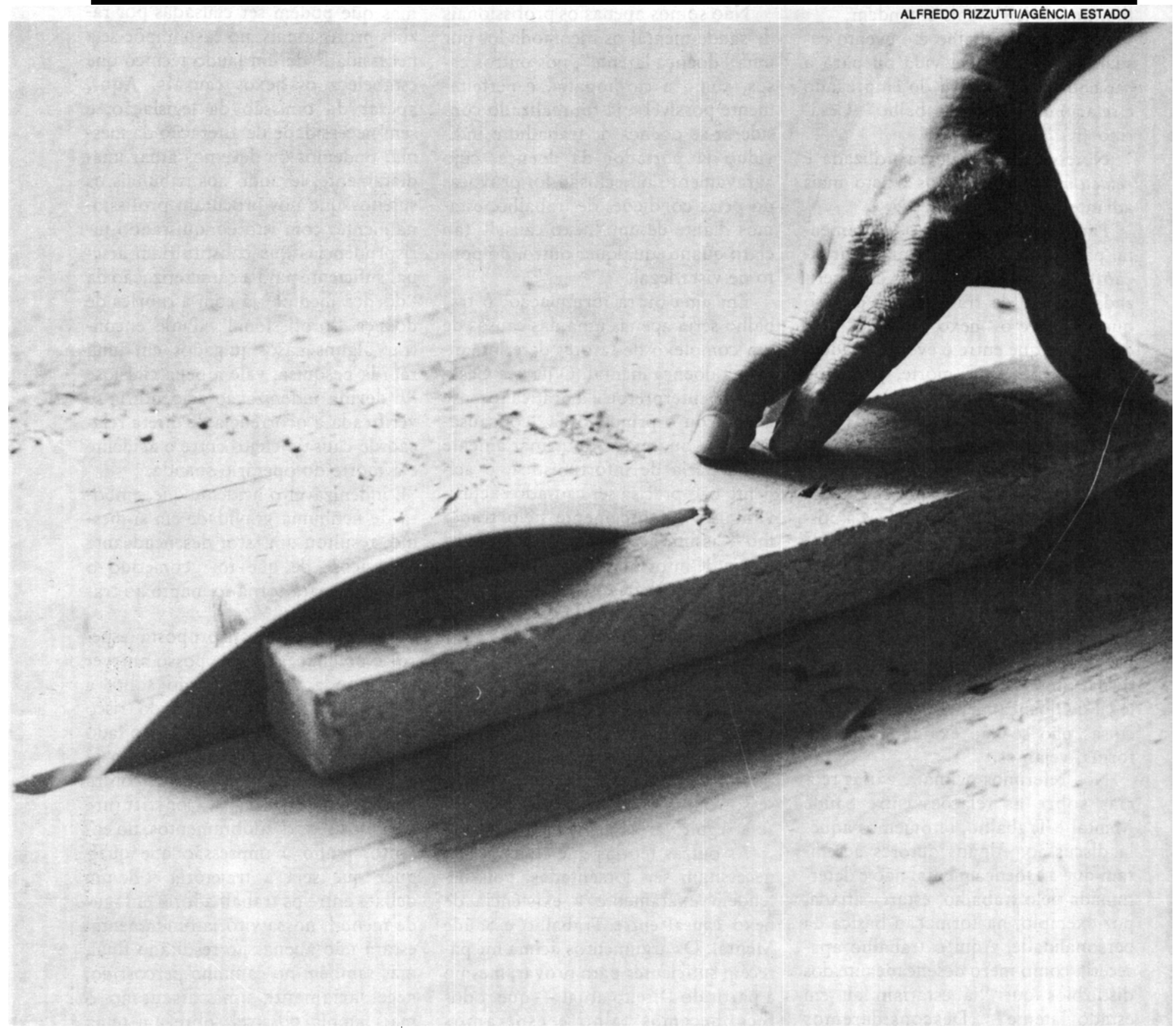

consumiu-se a neutralidade da técnica, esvaiu-se a parcimônia da lei.

É que a articulação obrigatória entre o "empregado" e o "empregador" livres, possuidores de si mesmo, e a mera compra e venda da força de trabalho sempre se deu (e só poderia) através da ostentação prosaica da primeira e a escaramuça da segunda, ato-contínuo, a luta pela dignidade do trabalho é empurrada a trajetória oposta: não é o que acontece, a nível superestrutural, em uma greve? Antes a disputa individual e sorrateira do trabalhador pela economia dos gestos, dos tempos (alongando matreiramente o tempo que dispóe para it ao banheiro, por exemplo). E agora, com as máquinas paradas, a negociação pública e escandalosa do valor dos gestos alugados. Não é por essas vias que o trabalhador posto como individual se reencontra com sua classe? A arquitetura das relações saúde-doenca no trabalho tem o mesmo destino, muda o "mote" segue a mesma "melodia".
Desnecessário dizer que o quadro se agrava quando o locus se transfere para as 'doenças do espírito', aqui o preconceito se agiganta, o silêncio se impōe.

É hora de escancarar a discussão sobre saúde mental e trabalho, tornála despudoradamente pública, política. Se surge da vida dos homens, que compareça ao mundo dos homens, pela porta da frente, sem subterfúgios.

\section{Uma luta possivel}

Por acidente ou doença do trabaPSICOLOGIA, CIÉNCIA E PROFISSÃO, 23 
lho, nossas leis atuais entendem:

"Acidente de trabalho é o evento casual, danoso para a vida ou para a capacidade laborativa do empregado e relacionada com o trabalho" (Cesarino $\mathbf{J r}$.)

Note-se que a palavra utilizada é relacionada, voltaremos a isto mais adiante.

Para efeitos jurídicos o fundamental para que uma "lesão ou perturbação funcional" venha a ser caracterizada como "de trabalho" é preciso que se prove, o "nexo causal", "a lei quer dizer que entre $o$ evento (acidente ou doença) e a morte, perda ou redução, haja uma cadeia de causa e efeito". Aqui parecem residir as dificuldades quando estamos no território da Saúde Mental, são confusos e mal determinados os nexos causais de qualquer doença mental, talvez a postura teórica mais correta seja a de eliminar o modelo simplista de mera atribuição causa-efeito, ou como querem alguns, partir, $a$ priori, da múltipla causação, ao traçar a Etiologia psicopatológica. Por isso objetar-se-á tornar impossivel o enquadramento legal da doença mental. Felizmente as coisas não se dão exatamente desta forma, vejamos.

Nos referimos acima a várias teorias sobre as relações entre Saúde Mental e Trabalho, retomemos aquela discussão. Alguns autores acreditam que a Doença mental não é determinada pelo trabalho, estaria sitiada, por exemplo, na formaçāo básica da personalidade. Aqui o trabalho apareceria como mero desencadeante dos distúrbios que "já estariam ali em estado latente". (Desconsideremos por ora o simplismo desta formulação, tomemo-la como verdadeira.)

Como se sabe a jurisprudência (casos já julgados) é quem dimensiona concretamente a aplicação da lei, resolve pela prática jurídica suas imprecisões ou omissões, veja o que ocorreu com as cardiopatias, estabelecendo uma maneira doutrinária de interpretação dos "nexos causais": "têm a jurisprudência e a doutrina admitido que as lesōes cardiacas provocadas por traumatismo ou por esforço físico violento e prolongado, em paciente predisposto já afetado por moléstia cardiaca, em estado latente, podem ser consideradas acidentes de trabatho (grifos nossos).
Não somos apenas os profissionais de saúde mental os incomodados por uma "doença latente", nos outros casos, como a cardiopatia, é perfeitamente possível e já foi tealizado considerar-se doença de trabalho o indivíduo já portador da doença, cujo agravamento,ou,eclosão foi provocado pelas condiçôes de trabalho, estamos diante de um "nexo causal" tão claro quanto qualquer outro, do ponto de vista legal.

Em uma outra formulação: o trabalho seria apenas uma das causas de um complexo de fatores determinantes da doença mental. O jurista Cesarino Jr. interpretou e a prática forense consagrou o princípio da "concausalidade", ou seja, "doutrinariamente em matéria de infortunística, 0 acidente não precisa ser causado exclusivamente e unicamente pelo trabalho", assim, a lei... reconhece a existência de infortúnio mesmo que o acidente não tenha causa única. É a concausalidade, que resulta da causa única, ou nexo etiológico,associada com outras causas independentes.

Uma outra jurisprudência deve ser lembrada aqui, já nos chamaram de ptofissionais da dúvida. Segundo os juristas é "pacífico" que: "Em caso de dúvida sobre o nexo causal, a questão se solve a favor do operário", citamse a seguir várias jurisprudências.

As outras teorias que citamos não necessitam ser comentadas, pois defendem exatamente a existência de nexo causal entre Trabalho e Saúde Mental. Os argumentos acima me parecem suficientes para provar, mesmo a partir do Direito atual - que todos reconhecemos falho e esperamos aperfeiçoar com a Constituinte $-\dot{e}$ perfeitamente possivel do ponto de vista jurídico o enquadramento das

"doenças mentais" como "doenças profissionais".

E politicamente, esta luta é viável? Sim, porque estamos em pleno periodo Constituinte, ao qual se seguirá o necessário ajuste das leis complementares, mas também por outra razão que considero importante destacar entre os profissionais, como estamos agora.

A legislação atual distingue as doenças profissionais das "doenças de trabalho", estas últimas seriam aquelas "atipicas", ou seja, não definidas, $a$ priori, como resultado do trabalho, mas que podem ser causadas por razōes profissionais, no caso impöe-se a necessidade de um laudo técnico que estabeleça os nexos causais. Aqui, apesar da omissão da legislação, e sem necessidade de alteraçāo da mesma, podemos ou devemos atuar imediatamente, levando aos tribunais os sujeitos que nos procuram profissionalmente, com isto conquistando jurisprudências que constituiriam arsenal suficiente para a caracterizaçāo da "doença mental" já com a rubrica de doença "profissional". Pude encontrar alguns casos julgados em uma rápida pesquisa, vale a pena citá-los: "É devida indenização acidentária se verificada a ocorrência de direta relação de causa e efeito entre $o$ acidente e a morte do operário suicida."

"É indenizável o acidente que, embora de nenhuma gravidade em si mesmo, resultou um fator desencadeante de psicose de que foi acometido o operário, para torná-lo inapto ao trabalho."

Evidentemente esta proposta (espero) é polêmica, no que posso antever existe toda uma discussão sobre a questāo da monetarizaçāo do risco que deve ser travada, por outro lado nos baseamos aqui na legislação já existente, a mesma que se encontra em mudança quer na Constituinte quer nos seus desdobramentos, no entanto, tenho a impressão que qualquer que seja a trajetória de um debate entre os trabalhadores em saúde mental, nossa vitória fundamental estará não apenas no resultado final, mas também no caminho percorrido, necessariamente uma discussão o mais ampla possível sobre um tema até agora "tabu".

Uma síntese destas reflexões? Será possível? Pelo menos palavras finais. Em 1981defendi minha tese de doutoramento, de lá para cá tenho estado a serviço de algumas linhas que compunham a conclusão: "Parafraseando Engels, só existe um fato psicológico: o homem precisa sobreviver". Ou de maneira um pouco mais provocativa: de onde vem a dor, a infelicidade, o infortúnio dos homens. Sem dúvida virá da vida dos homens mesmos. Os homens, o senso comum, o sentimento comum já sabe há muito tempo isto, nós, Psicólogos e Psiquiatras, trabalhadores em saúde mental, ainda necessitamos aprender? 